\title{
INFLUENCE OF HYDROPHOBIC RESIN COATING ON MICRO-TENSILE BOND STRENGTH OF DIFFERENT ADHESIVES: AN IN - VITRO STUDY
}

\author{
Marwa Mohamed Abbas Temirek *
}

\begin{abstract}
Recently, the etch-and-rinse and self-etching approaches are the two strategies of resin-based adhesive systems to accomplish the bonding to enamel and dentin. The increased amount of solvents and hydrophilic monomers in the adhesive formulations lead to greater amount of residual solvents entrapped in the adhesive layer. Consequently, the resulting polymers will be more susceptible to degradation over time. One of the methods for more durable bond includes the application of an additional layer of a hydrophobic resin coating over the polymerized simplified adhesive. The aim of this in -vitro study was to evaluate the influence of hydrophobic resin coating on micro-tensile bond strength of different adhesives Eighty freshly sound human molars were divided into three main groups according to method of bonding (A), where (A1) represents teeth bonded using Single Bond Universal Adhesive in total each approach, (A2) represents teeth bonded using Single Bond Universal Adhesive in self-etch approach while (A3) represents teeth bonded using Self Etch Future Single Bond DC Bonding System. Each (A) group will be then subdivided into two additional subgroups according to the addition of hydrophobic resin coating into (B1) which stands for teeth with additional hydrophobic resin coating and (B2) which stands for teeth without additional of hydrophobic resin coating. Each $(\mathrm{AB})$ group will be finally subdivided into two smaller subgroups according to the effect of thermocycling, where (T1) denotes the teeth which were thermocycled, and (T2) denotes the teeth which were not thermocycled. The occlusal dentin surface of each molar was prepared on two levels: Superficial level (below the dentino enamel junction by $0.5 \mathrm{~mm}$ ) and deep level (below the dentino enamel junction by $1.5 \mathrm{~mm}$ ). For all specimens, after bonding procedures either total etch or self etch, a hydrophobic resin coating was added for the assigned groups. Resin composite was applied; thermo-cycling was done for the assigned groups. Teeth were sectioned into a series of $1 \mathrm{~mm}$ thick slabs and microtensile bond strength testing was done. Two representative specimens of each group were selected for Ultramorphological Examination. Mode of application, addition of adhesive layer and thermocycling had a significant effect on bond strength. Within the limits of this study, we concluded that regarding bonding efficacy to enamel and dentine, conventional 3-step etch-and-rinse adhesives are still not surpassed by the newer simplified self etch adhesive systems. Addition of the hydrophobic bonding resin coating improved bonding to dentine especially when used with all-in-one self-etch adhesive systems.
\end{abstract}

* Lecturer of Conservative Dentistry, Faculty of Dentistry, Fayuom University. 


\section{INTRODUCTION}

Adhesion to dentin has been the subject of considerable interest over the last few decades, and dentin bonding agents have undergo dramatic changes in chemistry and clinical use. The bonding mechanism of adhesive systems basically involves the replacement of minerals removed from the hard dental tissue by resin monomers, in such a way that a polymer becomes interlocked to the dental substrate. Recently, the etch-and-rinse and selfetching approaches are the two strategies of resinbased adhesive systems to accomplish the bonding to enamel and dentin.(Tjäderhane, et al., 2014).

The etch-and- rinse approach involves the application of a phosphoric acid gel to both dental substrates which allows removal of the smear layer, exposure of the collagen fibrils in dentin and increase in surface area and surface energy of enamel. The primer is then applied followed by the bond .The main disadvantage of etch-and-rinse system, mainly two step versions, is that there is risk of collagen fiber collapse during the process of demineralized dentin drying, which leads to a decrease in bond strength.(Dentária \& Sezinando, 2014)

In the self-etch approaches (one step or two step), there is no need to apply phosphoric acid gel on dental substrate as dentin demineralization and priming occur simultaneously, (Sofan, Romeo, et al., 2017). The advantages of self-etch adhesives are less technique sensitive and the use of single step adhesives improved monomer penetration into tooth substrate.

The increased amount of solvents and hydrophilic monomers in the adhesive formulations lead to greater amount of residual solvents entrapped in the adhesive layer. The accumulation of hydrophilic monomer and especially residual solvents may hinder the formation of a high crosslinking polymer, decreasing the degree conversion which may reduce resin-dentin bond strengths, and increase permeability of the adhesive layer after polymerization. Consequently, the resulting polymers will be more susceptible to degradation over time. For these reasons, there are considerable recent interests in developing new methods to overcome the hydrolysis of the bond. One of the methods includes the application of an additional layer of a hydrophobic resin coating over the polymerized simplified adhesive. This extra resin coat aims at increasing the thickness and uniformity of the adhesive layer, as well as to reduce the fluid flow across the adhesive interface.(Yiu et al., 2005)

The aim of this in -vitro study was to evaluate the influence of hydrophobic resin coating on micro-tensile bond strength of different adhesives

\section{MATERIALS AND METHODS}

\section{I- Materials}

The materials used in this study were:-

1- Two types of bonding system:

A- Universal bonding system.

B- Self etch bonding system.

2- Hydrophobic resin coating.

3- Nano hybrid resin composite.

4- Acid Etchant

\section{II- Methods}

\section{1-Selection of the teeth:}

Eighty freshly sound non carious human freshly extracted molar teeth were selected for the study. The teeth were examined using a magnifying lens $\times 7$ to exclude teeth with cracks. The residual soft tissue was removed from the roots with a scalar. Teeth were rinsed with running water and stored in distilled water at $4^{\circ} \mathrm{C}$ until used.

\section{2-Mounting of teeth:}

Specially designed cylindrical teflon molds of $20 \mathrm{~mm}$ height and $17 \mathrm{~mm}$ internal diameter were 
constructed and filled with self-curing acrylic resin* All the teeth were embedded vertically in the teflon molds till the cemento-enamel junction allowing only teeth crowns to be shown.

\section{3- Grouping of teeth:}

The teeth were divided into three main groups according to method of bonding (A), where (A1) represents teeth bonded using Single Bond Universal Adhesive in total each approach, (A2) represents teeth bonded using Single

Bond Universal Adhesive in self-etch approach while (A3) represents teeth bonded using Self Etch Future Single Bond DC Bonding System.

Each (A) group will be then subdivided into two additional subgroups according to the addition of hydrophobic resin coating into (B1) which stands for teeth with additional hydrophobic resin coating and (B2) which stands for teeth without additional of hydrophobic resin coating. Each (AB) group will be finally subdivided into two smaller subgroups according to the effect of thermocycling, where (T1) denotes the teeth which were thermocycled, and (T2) denotes the teeth which were not thermocycled.

\section{4-Preparation of teeth:}

The occlusal dentin surface of each molar was prepared on two levels: Superficial level (below the dentino enamel junction by $0.5 \mathrm{~mm}$ ) and deep level (below the dentino enamel junction by $1.5 \mathrm{~mm}$ ).

For detecting the level of the dentino enamel junction (DEJ), two guiding grooves of the same depth and dimension were placed on the mesial and distal surfaces, using cylindrical flat ended diamond stone (ISO \#111/012) ${ }^{* *}$, mounted on high speed hand piece ${ }^{* * *}$ with copious air-water spray. Using a periodontal probe and lead black pencil, a line was drawn on the proximal surfaces parallel to the DEJ and below it by $0.5 \mathrm{~mm}$. The two lines on the proximal surfaces were then connected carefully through the buccal and lingual surfaces to form a circle around the tooth, representing the superficial level. Tooth structure above the line was cut and the occlusal surface was made flat to expose the superficial dentin level required. The superficial dentin level was parallel to the occlusal surface, perpendicular on the longitudinal axis of the tooth and $0.5 \mathrm{~mm}$ below DEJ. A line was then drawn on the middle of the flat occlusal surface dividing it into two equal halves (mesial and distal). Three points were placed to help drawing a line around one proximal half of the tooth, $1 \mathrm{~mm}$ below the superficial dentin level. The points were then connected to produce a line representing the deep dentin level.

A cylindrical flat ended diamond stone (ISO \#111/012) was used to produce deep dentin level (1.5 mm below DEJ), then the roots were poured in self cured transparent acrylic resin ${ }^{* * * *}$.

\section{5- Application of bonding system:}

a) Etch and rinse adhesive system:

The etchant was applied, left in place for 15 seconds and thoroughly rinsed for 10 seconds. Excess water was blotted using cotton bellets. Immediately after blotting, 2-3 consecutive coats of adhesive were applied to etched enamel and dentin with microbrush for 15 seconds with gentle agitation, air- thinned gently for 5 seconds and lightcured for 10 seconds. A hydrophobic resin coating was added as a very thin layer of heliobond with mirobrush on the dental surface and light-cured for 10 seconds for the assigned group.

\footnotetext{
* Acrostone, Dental Factory, Egypt

** Mani inc. Japan.

*** Advance co. $t$ 0611328, U.S.A

****Acrostone, Dental Factory, Egypt

***** Woodpecker Medical Instrument Company, Model LED.B. China
} 
TABLE (1): Materials' specification, composition, manufacturer and lot number

\begin{tabular}{|c|c|c|c|c|}
\hline Material & Specification & Composition & Manufacturer & Lot no. \\
\hline $\begin{array}{c}\text { Single Bond } \\
\text { Universal } \\
\text { Adhesive }\end{array}$ & $\begin{array}{c}\text { Universal } \\
\text { adhesive system }\end{array}$ & $\begin{array}{l}\text { MDP phosphate monomer } \\
\text {-Dimethacrylate resins } \\
\text {-HEMA } \\
\text {-Vitrebond }{ }^{\mathrm{TM}} \text { copolymer } \\
\text {-Filler } \\
\text {-Ethanol } \\
\text {-Water } \\
\text {-Initiators } \\
\text {-Silane }\end{array}$ & $\begin{array}{c}\text { 3M } \\
\text { Oral Care Solutions Division } \\
\text { 3M Center, St. Paul, } \\
\text { MN 55144-1000, USA } \\
\text { 1-888 } \\
\text { 3M HELPS (1-888-364 3577) }\end{array}$ & $\begin{array}{l}n \\
\infty \\
\infty \\
\infty \\
n\end{array}$ \\
\hline $\begin{array}{l}\text { Future } \\
\text { Single Bond } \\
\text { DC } \\
\text { Single dose }\end{array}$ & $\begin{array}{l}\text { Self Etch } \\
\text { Bonding } \\
\text { System }\end{array}$ & $\begin{array}{l}\text {-Dimethacrylate resins } \\
\text {-HEMA } \\
\text {-Vitrebond }{ }^{\mathrm{TM}} \text { copolymer } \\
\text {-Filler } \\
\text {-Ethanol } \\
\text {-Water } \\
\text {-Initiators }\end{array}$ & $\begin{array}{c}\text { VOCO GmbH } \\
\text { P.O. Box: } 767 \\
\text { 27457 Cuxhaven } \\
\text { Germany } \\
\text { Free Hotline: } \\
\underline{00800 / 44444555} \\
\text { Phone: }+494721 / 719-0 \\
\text { Fax: }+494721 / 719-109\end{array}$ & 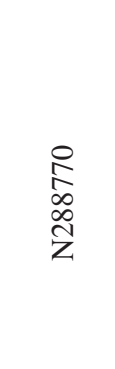 \\
\hline Heliobond & $\begin{array}{l}\text { Hydrophobic } \\
\text { resin coating }\end{array}$ & $\begin{array}{ll}\text { - } & \text { Bis-GMA. } \\
\text { - } & \text { Triethylene glycol dimethacrylate }\end{array}$ & $\begin{array}{c}\text { Ivoclar Vivadent AG Bendererstrasse } \\
\text { 2 FL-9494 Schaan } \\
\text { PRINCIPALITY OF } \\
\text { LIECHTENSTEIN } \\
\text { Tel: +423 } 2353535 \\
\text { Fax: +4232353360 }\end{array}$ & $\begin{array}{l}0 \\
\stackrel{2}{a} \\
\text { ๘ }\end{array}$ \\
\hline $\begin{array}{l}\text { Filtek }^{\mathrm{TM}} \\
\text { Z250 XT } \\
\text { Universal } \\
\text { Restorative }\end{array}$ & $\begin{array}{l}\text { Nano-filled } \\
\text { resin composite }\end{array}$ & $\begin{array}{l}\text {-Resins: } \\
\text { Bis-GMA } \\
\text { UDMA } \\
\text { TEGDMA } \\
\text { Bis-EMA } \\
\text { PEGDMA } \\
\text {-Fillers: Combination of non } \\
\text { agglomerated / nonaggregated silica } \\
\text { filler, zirconia filler, zirconia/silica } \\
\text { cluster filler }\end{array}$ & $\begin{array}{c}\text { 3M } \\
\text { Oral Care Solutions Division } \\
\text { 3M Center, St. Paul, } \\
\text { MN 55144-1000, USA } \\
\text { 1-888 } \\
\text { 3M HELPS (1-888-364-3577) }\end{array}$ & 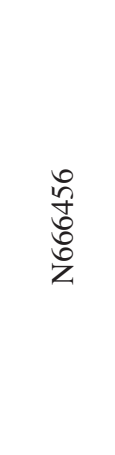 \\
\hline $\begin{array}{l}\text { Scotchbond } \\
\text { Etchant }\end{array}$ & Acid etch & $\begin{array}{l}\text { Water } 55-66 \% \text { w.t Phosphoric acid } \\
\text { 30-40\% w.t } \\
\text { Synthetic Amorphous silica } \\
\text { w.t }\end{array}$ & $\begin{array}{l}\text { 3M Oral Care Solutions Division } \\
\text { 3M Center, St. Paul, } \\
\text { MN 55144-1000, USA } \\
\text { 3M HELPS } \\
(1-888-364-3577)\end{array}$ & 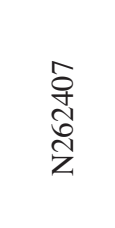 \\
\hline
\end{tabular}


b) Application of self-etch adhesive system:

The bonding system was applied 2-3 consecutive coats of adhesive were applied to etched enamel and dentin with microbrush for 15 seconds with gentle agitation, air- thinned gently for 5 seconds and lightcured for 20 seconds. A hydrophobic resin coating was added as a very thin layer of heliobond with mirobrush on the dental surface and light-cured for 10 seconds for the assigned group. All light curing steps were done using a light emitting diode (850$1000 \mathrm{~mW} / \mathrm{cm} 2$ intensity) ${ }^{*}$.

\section{6-Application of nanofilled resin composite:}

Tofflemire matrix system was used to support resin composite during packing and hardening. Resin composite was applied in two increments by packing each increment on the bonded surface using gold plated composite applicator and light cured for 20 seconds.

\section{7-Thermal cycling procedures for laboratory test- ing of dental restorations}

In this study, thermo-cycling was done through 500 cycles. Dwell times were $15 \mathrm{~s}$. in each water bath $^{* *}$ with a lag time $10 \mathrm{~s}$. The low-temperature point was $5{ }^{\circ} \mathrm{C}$ and the high-temperature point was $55^{\circ} \mathrm{C}$.

\section{8-Micro-tensile bond strength sample preparation}

Each tooth was mounted on the cutting machine ${ }^{* * *}$ and sectioned into a series of $1 \mathrm{~mm}$ thick slabs under water cooling. The sectioning was performed using a diamond disc of 4 "diameter x $0.3 \mathrm{~mm}$ thickness x 0.5 " arbor impregnated diamond cutting blades with wear-resistant Ti-C coating for low speed saw $^{* * * *}$. Again, by rotating the tooth $90^{\circ}$ and further sectioning it lengthwise, sticks of $1.0 \mathrm{~mm} 2$ crosssection area were obtained. The central sticks from each specimen were selected and their thickness was checked using a caliper. The specimens were then subjected to the microtensile bond strength testing at a crosshead speed of $0.5 \mathrm{~mm} / \mathrm{min}$, at a materials testing machine ${ }^{* * * * *}$. Data were recorded using computer software ${ }^{* * * * * *}$. Data were collected and statistically analyzed.

\section{9- Ultramorphological Examination:}

Two representative specimens of each group were selected. The tooth roots were then sectioned by using cylindrical flat ended diamond stone (ISO \#111/012) mounted on high speed hand piece with copious air-water spray. A guiding groove was done at the middle of all the tooth surfaces in a buccolingual direction and the tooth was longitudinally sectioned into mesial and distal halves by repeated constant strokes using chisel and mallet. Another guiding groove was done at the middle of each half in a bucco-lingual direction to produce both superficial and deep dentin levels then it was sectioned. The cut surfaces were polished with descending grits of Soflex discs ${ }^{* * * * * * * *}$ to obtain highly flat and smooth surface. The polished surfaces were immersed in $6 \mathrm{ml} / \mathrm{L}$ hydrochloric acid $(\mathrm{HCl})^{* * * * * * * * *}$ for 30 seconds to remove the smear layer, and then rinsed in distilled water. The samples were further immersed in $5.25 \%$ sodium hypochlorite $(\mathrm{NaOCl})$ for 10 minutes to remove free un-encapsulated collagen. This procedure dissolved a small amount of tooth structure away from the tubular resin tags, leaving them standing in relief above the remaining

\footnotetext{
* Robota automated thermo-cycle; BILGE, Turkey

** Bronwill; E. McGrath Inc, 35 Osborne Street Salem MA 01970 v: 978-744-3546 f: 978-741-4020

*** IPDB40305, MTI Corporation 860 South 19th Street, Richmond, CA 94804, USA

**** LLOYD instruments, LR 5K, England) with a load cell of $5 \mathrm{KN}$

***** Nexygen-MT Lloyd Instruments.

******* 3M ESPE Company. U.S.A.

******* Piochem. Company, Egypt
} 
tooth structure. Specimens were then washed with distilled water and dehydrated through immersion in $99.9 \%$ ethyl alcohol ${ }^{*}$ for 30 seconds, then left to dry. Environmental Scanning Electron Microscope $(\text { ESEM })^{* *}$ was used to analyze resin-dentin interface operated with back scattered electron mode at 1500x magnification.

\section{RESULTS}

Data presented as mean and standard deviation (SD). Data explored for normality using Kolmogorov-Smirnov and Shapiro-Wilk tests. Bond strength showed a parametric distribution, so Three-Way ANOVA used to study the effect of different Mode of application, addition of adhesive layer and Thermocycling followed by post-hoc test with Bonferroni correction for pairwise comparison $(\alpha=0.05)$. Statistical analysis was performed with statistical package for social science (IBM SPSS Statistics for Windows, Version 23.0. Armonk, NY: IBM Corp).

Three-way ANOVA showed that mode of application, addition of adhesive layer and thermocycling had a significant effect on bond strength at $\mathrm{p} \leq 0.001,0.003$ and $\leq 0.001$ respectively. U/TE showed the highest bond strength after TC compared to other groups for $+\mathrm{H}$ and $-\mathrm{H}$. no difference between different tested modes of application before TC. No significant difference between $+\mathrm{T}+\mathrm{H},+\mathrm{T}-\mathrm{H},-\mathrm{T}+\mathrm{H}$, and $-\mathrm{T}-\mathrm{H}$ for $\mathrm{U} / \mathrm{TE}$. TC with $-\mathrm{H}$ application showed the lowest bond strength followed by $+\mathrm{TC}+\mathrm{H}$; and the significant highest value for $+\mathrm{H}$ and $-\mathrm{H}$ without $\mathrm{TC}$ with any significant difference between them. The same resulted for FDC/SE.

Table (2) Bond strength data for different tested groups

\begin{tabular}{|c|c|c|c|c|c|}
\hline \multicolumn{2}{|c|}{} & U/TE & U/SE & F DC/SE & p-value \\
\hline \multirow{2}{*}{$+\mathbf{T C}$} & $+\mathrm{H}$ & $31.08 \pm 6.13^{\mathrm{b}}$ & $15.17 \pm 2.76^{\mathrm{aB}}$ & $14.71 \pm 3.1^{\mathrm{aB}}$ & $\leq 0.001^{*}$ \\
\cline { 2 - 6 } & $-\mathrm{H}$ & $30.78 \pm 10.63^{\mathrm{b}}$ & $3.12 \pm 1.13^{\mathrm{aA}}$ & $3.59 \pm 1.43^{\mathrm{aA}}$ & $\leq 0.001^{*}$ \\
\hline \multirow{2}{*}{$-\mathbf{T C}$} & $+\mathrm{H}$ & $26.32 \pm 9.53$ & $26.43 \pm 8.89^{\mathrm{C}}$ & $32.36 \pm 7.54^{\mathrm{C}}$ & $0.292 \mathrm{NS}$ \\
\cline { 2 - 6 } & $-\mathrm{H}$ & $30.15 \pm 10.26$ & $22.99 \pm 6.12^{\mathrm{C}}$ & $21.55 \pm 5.25^{\mathrm{C}}$ & $0.117 \mathrm{NS}$ \\
\hline
\end{tabular}

Different lowercase letters within each row indicates significant different at $p \leq 0.05$.

Different uppercase letters within each column indicates significant different at $p \leq 0.05$.

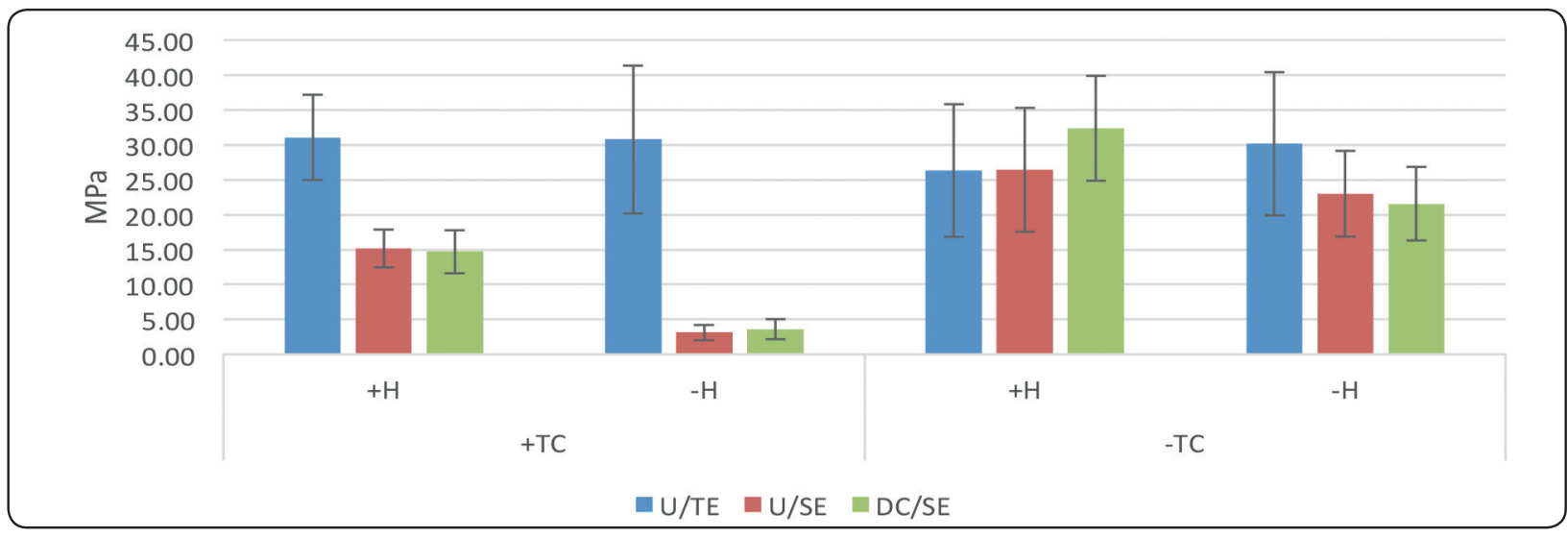

Fig. (1) Bar chart for mean bond strength (MPa).

\footnotetext{
* International company for support and medical industries, batch number:6688, Egypt

** Fei Company, model: Quanta 200, Germany.
} 


\section{Results of ESEM}

ESEM photomicrographs of Universal Adhesive used with Etch and rinse approach represented three distinct layers; dentin, hybrid and resin layers were apparent. Thick, consistent and solid resin layer was seen with no gaps. Homogenous, thick hybrid layer appeared with many resin tags of variable lengths penetrating inside the dentinal tubules, which is arranged perpendicular to the interface that appeared as well formed, long and thin resin tags, fig 2(A).

ESEM photomicrographs of Universal Adhesive used with self-etch approach, they revealed the same as the previous findings except that few, short and thin resin tags were seen extending inside the dentinal tubules, which were arranged perpendicular to the adhesive layer. The hybrid layer appeared thin and not continuous. fig 2(B)

ESEM photomicrographs of self-etch adhesive system Future Single Bond DC represented enhance dentin wettability and monomer infiltration and thin hybrid layer as seen in fig 2(C) ESEM photomicrographs of samples after addition of hydrophobic resin coating showed increased thickness and uniformity of adhesive layer fig 2(D).
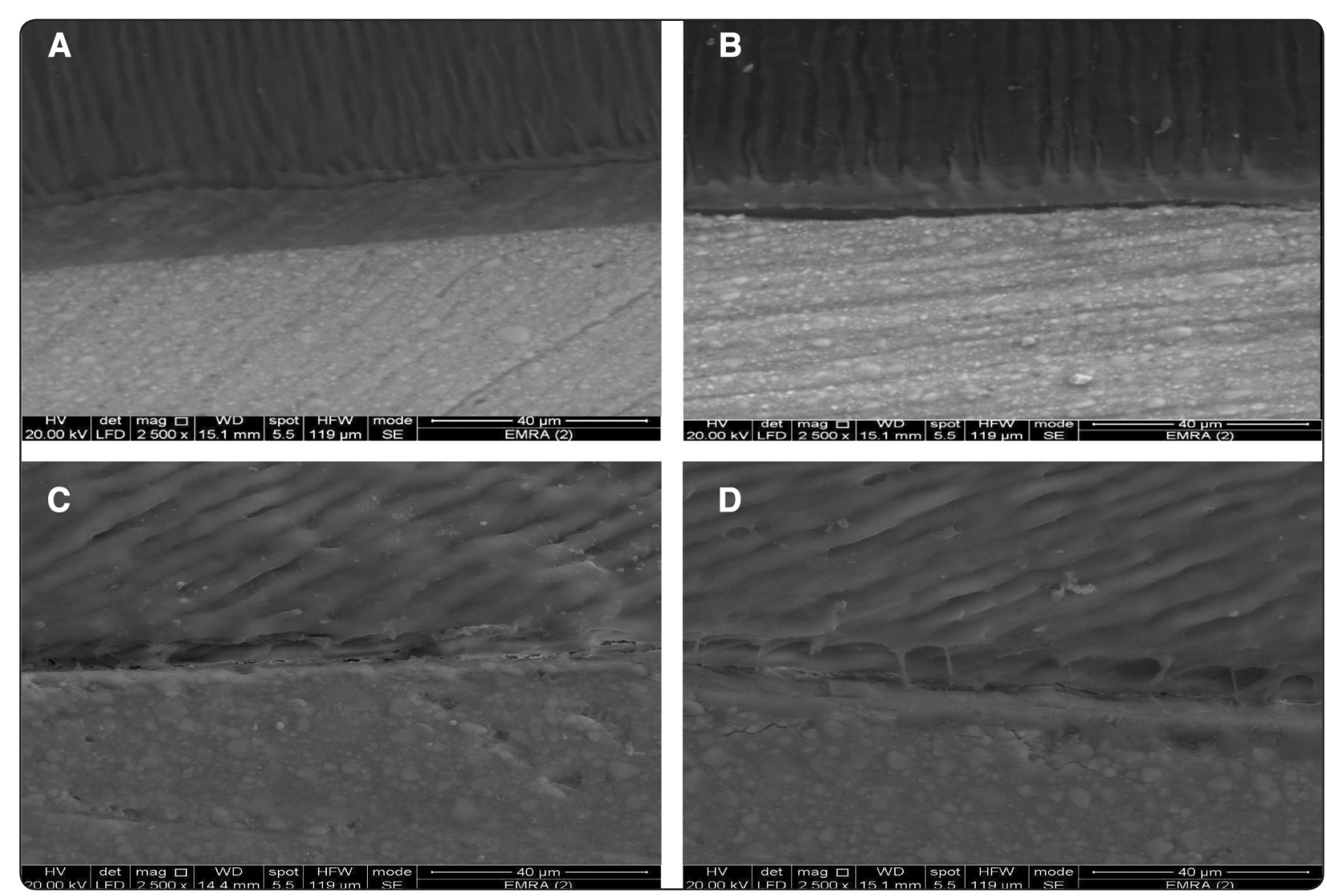

Fig. (2) ESEM photomicrographs of: Universal Adhesive used with Etch and rinse approach, (A) Universal Adhesive used with self-etch approach, fig (B) Self-etch adhesive system Future Single Bond DC, (C) Samples with hydrophobic resin coating, (D) 


\section{DISCUSSION}

Durable adhesion of dental materials to tooth substrates is indispensable for clinical success with tooth-coloured restorative materials that shrink on polymerization. When direct resin composites are bonded to tooth structures using dentine adhesives, the initial and residual polymerization stresses that are present along the cavity walls may result in gap formation, leakage, recurrent caries and pulpal irritation. The detrimental effect of marginal gap formation cannot be offset even with the use of fluoride-releasing adhesives or restorative materials that prevent demineralization along cavity margins, thus, only hermetic sealing of restorations guarantees clinical success.(Frankenberger \& Tay, 2005)

The performance of the universal adhesives used in this study was dependent on the adhesive strategy. The results of the $\mu$ TBS testing showed that tested adhesive systems showed significant enhanced resin-dentine bond strengths when used in etch and rinse mode, following manufacturers' directions. The presence of the smear layer imposes a physical barrier against the penetration of resin monomers. Phosphoric acid etching removes the smear layer, promotes superficial dentine demineralization and increases the impregnation of resin monomers, which leads to the creation of a thick hybrid layer fully integrated with dentin.

Compositional differences between adhesives may play an important role on the adhesive performance. Single Bond Universal Adhesive contains 10-methacry- loyloxydecyl dihydrogen phosphate monomer (MDP) capable to chemically interact with the hydroxyapatite by the formation of a stable nano-layering at the adhesive interface. Despite the fact that the increased acidity may lead to hydrolysis of the ester bond from the acid monomer results in a strong phosphoric acid that might increase the demineralization over time and explain the intense nanoleakage within the hybrid layer.
Some authors claimed that Single Bond Universal Adhesive performed generally similar when used in the Etch and rinse and self-etch adhesive mode. They referred that as SBU has polyalkenoic acid copolymer and MDP in its formulation. Although both molecules may compete by binding to the calcium in hydroxyapatite, they are usually associated with improved adhesive performance, which may explain the good performance of SBU in both bonding strategies.

On the other hand, self etch adhesive mode represented significantly lower bond strength which is may be explained as the demineralization byproducts, as well as the smear layer remnants, may have acted as contaminants, preventing the polymer chains from getting closer during the polymerization reaction. Developed resin adhesives contain more acidic hydrophilic monomers, and higher amounts of water to improve monomer impregnation into wet dentin substrate, resulting in lower degrees of polymerization of adhesive resin.(Sofan et al., 2017)

It is suggested that active application mode increases the resin-dentine bond strength. Several factors may account for this outcome. It is believed that an increased penetration of monomers into dentine substrates as well as higher solvent evaporation occurs under active application. Agitation also improves the polymerization efficacy through enhancing the chemical interaction with tooth substrate. Additionally, unreacted acidic resin monomers from the superficial layer of the adhesive can be taken to the basal portion of dentine, increasing the substrate demineralization, monomer diffusion and better interaction with the smear layer and underlying dentine.

HEMA is a hydrophilic monomer added to self-etch adhesives to enhance dentin wettability and monomer infiltration and prevent hydrophobic monomer/water phase separation. The incorporation of poly-HEMA in the polymer net-work enhances water uptake after polymerization, due to poly- 
HEMA hydrolytic degradation and elution of byproducts during long-term storage(Labib, et,al, 2017). HEMA-containing adhesives are more hydrophilic and have higher water sorption. In long-term water storage, the reduction in the tensile strength of adhesives increases with their hydrophilicity, reducing their mechanical properties

One of the methods used to bypass these drawbacks includes the application of an additional layer of a hydrophobic resin coating over the polymerized simplified adhesive. This extra resin coat aims at increasing the thickness and uniformity of the adhesive layer, as well as to reduce the fluid flow across the adhesive interface, (Munoz et al., 2014). Excellent in vitro and clinical results have been reported after placement of a hydrophobic resin coating over 1-step self etch adhesives. The extra layer of hydrophobic resin adds unsolved hydrophobic monomers to the adhesive interface, which decreases the relative concentration of retained solvents and unreacted monomers in the adhesive layer.

This, in turn, increases the ultimate tensile strength of the adhesive interface, due to the formation of a more densely packed hybrid layers, making it more resistant to the tensile forces during $\mu$ TBS testing and less prone to degradation effects over time. This explains the significant improved performance after addition of hydrophobic resin coating. This agrees with the findings of Munoz et al., 2014) who claimed thatthe use of a hydrophobic resin coating may improve the performance of the universal adhesives mainly when applied as self etch adhesives. Others approved that an extra hydrophobic layer coating improved the immediate in vitro performance $\mu \mathrm{TBS}$ and nanoleakage of the universal adhesive systems that were studied in self etch mode, (Labib, et al., 2017) they found less submicron defects, such as solvent/water entrapment, incomplete resin infiltration, or areas of inadequate polymerization.

\section{CONCLUSIONS}

Within the limits of this study, we can conclude that:

1- Regarding bonding efficacy to enamel and dentine, conventional 3-step etch-and-rinse adhesives are still not surpassed by the newer simplified self etch adhesive systems.

2- Addition of the hydrophobic bonding resin coating improved bonding to dentine especially when used with all-in-one self-etch adhesive systems.

\section{REFERENCES}

1. Abdalla AI.: Effect of long-term water aging on microtensile bond strength of self-etch adhesives to dentin. Am J Dent. 2010, 23: 29-33.

2. Bin Yang, Ludwig K., Adelung R. and Kern M.: Microtensile bond strength of three luting resins to human regional dentin. Dental Materials 2006, 22: 45-56.

3. Breschia L., Mazzonib A., Ruggerib A., Cadenaroa M., Di Lenardaa R. and Dorigoa E.D.: Dental adhesion review: Aging and stability of the bonded interface. Dental materials 2008, 24: 90-01.

4. Cantanhede de Sá R.B., Oliveira C.A., Puppin R.M., Ambrosano G.M., Nikaido T., Tagami J. and Giannini M.: Effects of Water Storage on Bond Strength and Dentin Sealing Ability Promoted by Adhesive Systems. J. Adhes Dent., 2012, 14: 543-9.

5. Cardoso P.C., Lopes G.C., Vieira L.C. and Baratieri L.N.: Effect of Solvent Type on Microtensile Bond Strength of a Total-etch One-bottle Adhesive System to Moist or Dry Dentin. Operative Dentistry, 2005, 30: 376-81.

6. Carrilho M.R., Franklin R.T., David H. P., Leo T. and Carvalho M.R.: Mechanical stability of resin-dentin bond components. Dental Materials, 2005, 21: 232-41

7. De Munck J, Vargas M, Iracki J, Van Landuyt K, Poitevin A, Lambrechts P. and Van Meerbeek B.: One-day bonding effectiveness of new self-etch adhesives to bur-cut enamel and dentin. Oper. Dent. 2005, 30: 39-49.

8. Dentária,M., \& Sezinando,A. (2014). Looking for the ideal adhesive - A review. Revista Portuguesa de Estomatologia, Medicina Dentária e Cirurgia Maxilofacial, 55(4), 194206. https://doi.org/10.1016/j.rpemd.2014.07.004 
9. El-Zohairy A.A., de Gee A.J., de Jager N., van Ruijven L.J. and Feilzer A.J.: The influence of specimen attachment and dimension on microtensile strength. J Dent Res 2004, 83: 420-24Esra C.S., Nakajima M., Senawongse P., Soyman M., O” zer F., Ogata M. and Tagami J.: Microtensile bond strength of a filled vs. unfilled adhesive to dentin using self-etch and total-etch technique. Journal of Dentistry 2006, 34: 283-91.

10. Ferrari M., Goracci C., Sadek F.T. and Cardoso P.E.: Microtensile bond strength tests: SEM evaluation of samples integrity before testing. The European Journal of Oral Sciences 2002, 110: 385-91.

11. Frankenberger, R., \& Tay, F. R. (2005). Self-etch vs etchand-rinse adhesives : effect of thermo-mechanical fatigue loading on marginal quality of bonded resin composite restorations. Dental Materials, 21, 397-412. https://doi. org/10.1016/j.dental.2004.07.005

12. Garcia R.N., De Goes M.F. and Giannini M.: Effect of water storage on bond strength of self-etching adhesives to dentin. J Contempt Dent Pract., 2007, 1: 46-53.

13. Goracci C., Sadek F.T., Monticelli F., Cardoso P.E.C. and Ferrari M.: Influence of Substrate, Shape, and Thickness on Microtensile Specimens' Structural Integrity and Their Measured Bond Strengths. Dental Materials, 2004; 20: 643-54

14. Guimarães L.F., Almeida J., Wang L., D’Alpino P. and Garcia F.: Effectiveness of immediate bonding of etchand-rinse adhesives to simplified ethanol-saturated dentin. Braz. Oral Res., 2012, 26: 220-32. Hashimoto M., Ohno H., Sano H., Kaga M. and Oguchi H.: Degradation patterns of different adhesives and bonding procedures. J. Biomed. Mater. Res. B. Appl, 2003, 324: 15-30.

15. Jan De Munck, Mine A., Cardoso M.V., Neves A.D., Kirsten L. Van Landuyt, Poitevin A. and Meerbeek B.V.: Effect of dentin location and long-term water storage on bonding effectiveness of dentin adhesives. Dental Materials Journal 2011; 30: 7-13

16. Knobloch L.A., Gailey D., Azer S., Johnston W.M., Clelland N. and Kerby R.E.: Bond strengths of one- and twostep self-etch adhesive systems. J Prosthetic. Dent., 2007, 97: $216-22$

17. Labib, L. M., Nabih, S. M., \& El-marakby, A. M. (2017) Influence of Heliobond on Immediate Nanoleakge and Microtensile at Resin-Dentin Interface ( An In Vitro Study). International Journal of Dental Sciences and Research, 5(6), 150-158. https://doi.org/10.12691/ijdsr-5-6-4

18. Martins G.C., Ayala A.S., Calixto A.L., Gomes O., Gomes J. and D'Alpino P.: Interfacial integrity of bonded restorations with self-etching adhesives: Water storage and thermo mechanical loading. European Journal of Dental Research, 2012, 6: 169-77.

19. Munoz, M. A., Luiza, A., Reis, A., Loguercio, A. D., Hellen, N., \& Perdiga, J. (2014). Influence of a hydrophobic resin coating on the bonding efficacy of three universal adhesives. Journal of Dentistry, 42, 595-602. https://doi. org/10.1016/j.jdent.2014.01.013

20. Sofan, E., Romeo, U., Migliau, G., \& Migliau, G. (2017). Classification review of dental adhesive systems : from the IV generation to the universal type Corresponding author : Annali Di Stomatologia, VIII (1), 1-17.

21. Tjäderhane, L., Nascimento, F. D., Breschi, L., Mazzoni, A., Tersariol, L. S., Geraldeli, S., Pashley, D. H. (2014). Optimizing dentin bond durability: strategies to prevent hydrolytic degradation of the hybrid layer. Dent Mater, 29(10), 9991011. https://doi.org/10.1016/j.dental.2013.07.016.

22. Yiu, C. K. Y., Pashley, E. L., Hiraishi, N., King, N. M., Goracci, C., Ferrari, M., Tay, F. R. (2005). Solvent and water retention in dental adhesive blends after evaporation. Biomaterials, 26, 6863-6872.https://doi.org/10.1016/j.biomaterials. 2005.05.011 